\title{
Production of 5-hydroxymethylfurfural from wood by ionic liquid treatment
}

\author{
${\text { Ryoya } \text { Ito }^{1} \cdot \text { Hisashi Miyafuji }}^{1} \cdot$ Yuya Miyazaki $^{2} \cdot$ Takuya Kawai $^{2}$
}

Received: 15 January 2016/ Accepted: 28 March 2016/Published online: 19 April 2016

(C) The Japan Wood Research Society 2016

\begin{abstract}
Hydroxymethylfurfural (5-HMF) is one of the most important platform intermediates for the future synthesis of liquid transportation biofuel and other valuable compounds. This study aimed to identify ionic liquids that can convert wood into 5-HMF without catalysts. Glucose was converted into 5-HMF without catalysts in ionic liquids that contain sulfonyl groups, such as 1-ethyl-3methylimidazolium hydrogensulfate ([EMIM] $\left.\mathrm{HSO}_{4}\right)$ and 1-ethyl-3-methylimidazolium $\rho$-toluenesulfonate ([EMIM]Tos). However, [EMIM]Tos produced less 5-HMF from cellulose and wood, compared with [EMIM] $\mathrm{HSO}_{4}$. This is due to the difference of ability to decompose cellulose and wood between these ionic liquids. Consequently, among various ionic liquids studied, [EMIM] $\mathrm{HSO}_{4}$ achieved the highest yield of 5-HMF from wood and cellulose at 4.5 and $10.2 \mathrm{wt} \%$ yields, respectively, after $10 \mathrm{~h}$ at $140{ }^{\circ} \mathrm{C}$.
\end{abstract}

Keywords Japanese cedar · Cellulose · Glucose · 5-Hydroxymethylfurfural $\cdot$ Ionic liquid

Hisashi Miyafuji

miyafuji@kpu.ac.jp

1 Division of Environmental Sciences, Graduate School of Life and Environmental Sciences, Kyoto Prefectural University, Hangi-cho, Shimogamo, Sakyo-ku, Kyoto 606-8522, Japan

2 Project Planning Group, Project Development Department, Plant Project Center, Energy and Plant Operations, IHI Corporation, Toyosu IHI Building, 1-1, Toyosu 3-chome, Koto-ku, Tokyo 135-8710, Japan

\section{Introduction}

In recent years, biomass has attracted attention as a raw material for the production of liquid fuels and fine chemicals, because fossil resources are in danger of running out [1]. Crops, such as corn and sugarcane, have been transformed into liquid fuels, such as ethanol. However, the use of edible biomass can lead to soaring prices and global scarcity of food [2]. Thus, the use of inedible biomass, such as wood, should be promoted for the production of liquid fuels and fine chemicals [3, 4]. However, it is difficult to convert wood into such products inexpensively [5]. Among the various chemicals that can be produced from wood, 5-hydroxymethylfurfural (5-HMF) is an important platform intermediate for synthesizing liquid transportation biofuels and other valuable compounds [6-8]. However, 5-HMF is not yet produced on an industrial scale mainly because of its high production cost $[9,10]$. To overcome this problem, ionic liquid technology has attracted significant attention.

Ionic liquids are organic salts that are composed of cations and anions that give melting points near ambient temperature. They are thermally stable and have low vapor pressures, low toxicities, and extensive solvation capabilities [11]. Because some ionic liquids can dissolve the major wood components, cellulose, hemicellulose, or lignin, it is suggested that they can be used in biorefineries or chemical processing of wood [12-15]. In particular, their solvation capabilities can be applied to the production of 5-HMF from wood and its components.

Zhao et al. [16] studied reaction systems using the ionic liquid 1-ethyl-3-methylimidazolium chloride ([EMIM]Cl), with chromium (II) chloride $\left(\mathrm{CrCl}_{2}\right)$ as a catalyst. This system enabled the conversion of glucose into 5-HMF with yields of $70 \mathrm{~mol} \%$, and their results have encouraged conversion of disaccharides, cellulose, and lignocellulosics 
to 5-HMF in ionic liquids [17-22]. These studies suggest that 5-HMF can be produced from lignocellulosics without requiring preprocessing steps, such as delignification and hydrolysis.

In the reports described above, however, production of 5-HMF from biomass in ionic liquids has included the use of catalysts [23]. In such reaction system, production of 5 -HMF is mainly due to the catalysts, and ionic liquids are thought to be a solvent. Our previous study revealed that some ionic liquids are multifunctional reagent to dissolve and decompose cellulose. In this study, therefore, we studied the formation of 5-HMF from Japanese cedar (Cryptomeria japonica) in various ionic liquids without the use of catalyst to clarify their potential to produce 5-HMF from lignocellulosics. In particular, the reactions of cellulose and glucose were investigated.

\section{Materials and methods}

\section{Samples and chemicals}

Table 1 lists the ionic liquids that were used in this study. 5-HMF, glucose, fructose, cellobiose, cellotriose, levoglucosan, 1,6-anhydro- $\beta$-D-glucofuranose (AGF), acetonitrile, sodium sulfate, and acetic acid were purchased from Wako Pure Chemical Industries (Osaka, Japan). N,OBis(trimethylsilyl)trifluoroacetamide (BSTFA) and dehydrated dimethyl sulfoxide were purchased from SigmaAldrich (St Louis, MO, USA). Sodium chlorite and pyridine were purchased from Kanto Chemicals (Tokyo, Japan). Cellulose sample (Whatman CF1) was dried in an oven at $105{ }^{\circ} \mathrm{C}$ for $24 \mathrm{~h}$ before use. Wood flours from Japanese cedar (C. japonica) $(90-180 \mu \mathrm{m})$ were extracted

Table 1 Ionic liquids used in this study

\begin{tabular}{|c|c|c|}
\hline Ionic liquids & Abbreviations & Manuf. \\
\hline 1-Methylimidazolium bis(trifluoromethylsulfonyl)imido & {$[\mathrm{MIM}] \mathrm{NTf}_{2}$} & Sigma-Aldrich \\
\hline 1-Ethylimidazolium nitrate & {$[\mathrm{EIM}] \mathrm{NO}_{3}$} & IoLiTec \\
\hline 1,3-Dimethylimidazolium dimethyl phosphate & [DMIM]DMP & IoLiTec \\
\hline 1,3-Dimethylimidazolium bis[oxalato(2-)-O, $\mathrm{O}^{\prime}$ ]borate & [DMIM]BOB & Merck \\
\hline 1-Ethyl-3-methylimidazolium chloride & {$[\mathrm{EMIM}] \mathrm{Cl}$} & TCI \\
\hline 1-Ethyl-3-methylimidazolium hydrogensulfate & {$[\mathrm{EMIM}] \mathrm{HSO}_{4}$} & TCI \\
\hline 1-Ethyl-3-methylimidazolium methylphosphate & {$\left[\mathrm{EMIM} \mathrm{MPO}_{4}\right.$} & Kanto Chemical \\
\hline 1-Ethyl-3-methylimidazolium acetate & [EMIM]Ac & Sigma-Aldrich \\
\hline 1-Ethyl-3-methylimidazolium hexafluorophosphate & {$\left[\mathrm{EMIM} \mathrm{PF}_{6}\right.$} & TCI \\
\hline 1-Ethyl-3-methylimidazolium tetrachloroaluminate & {$[\mathrm{EMIM}] \mathrm{AlCl}_{4}$} & Sigma-Aldrich \\
\hline 1-Ethyl-3-methylimidazolium tetracyanoborate & {$[\mathrm{EMIM}] \mathrm{TCB}$} & Merck \\
\hline 1-Ethyl-3-methylimidazolium $\rho$-toluenesulfonate & [EMIM]Tos & TCI \\
\hline 1-Ethyl-3-methylimidazolium methanesulfonate & [EMIM]Mes & IoLiTec \\
\hline 1-Butyl-3-methylimidazolium thiocyanate & {$[\mathrm{BMIM}] \mathrm{SCN}$} & TCI \\
\hline 1-Butyl-3-methylimidazolium tetrafluroborate & {$[\mathrm{BMIM}] \mathrm{BF}_{4}$} & TCI \\
\hline 1-Butylpyridinium bis(fluorosulfonyl)imido & {$[\mathrm{BPr}] \mathrm{FSI}$} & Kanto Chemical \\
\hline 1-Buthylpyridinium hexafluorophosphate & {$[\mathrm{BPr}] \mathrm{PF}_{6}$} & TCI \\
\hline 1-Methyl-1-propylpyrrolidinium hexafluorophosphate & {$[\mathrm{MPPyr}] \mathrm{PF}_{6}$} & IoLiTec \\
\hline 1-Methyl-1-propylpiperidinium hexafluorophosphate & {$[\mathrm{MPPip}] \mathrm{PF}_{6}$} & IoLiTec \\
\hline Tetrabutylammonium chloride & {$\left[\mathrm{N}_{4444}\right] \mathrm{Cl}$} & TCI \\
\hline Tetrabutylammonium bromide & {$\left[\mathrm{N}_{4444}\right] \mathrm{Br}$} & TCI \\
\hline Tetrabutylammonium dichlorobromide & {$\left[\mathrm{N}_{4444}\right] \mathrm{Cl}_{2} \mathrm{Br}$} & TCI \\
\hline Tetrabutylammonium azide & {$\left[\mathrm{N}_{4444}\right] \mathrm{N}_{3}$} & TCI \\
\hline Tetrabutylammonium salicylate & {$\left[\mathrm{N}_{4444}\right] \mathrm{Sal}$} & TCI \\
\hline Tributhylethylphosphonium diethylphosphate & {$\left[\mathrm{P}_{4442}\right] \mathrm{DEP}$} & IoLiTec \\
\hline Trihexyltetradecylphosphonium hexafluorophosphate & {$\left[\mathrm{P}_{14,666}\right] \mathrm{PF}_{6}$} & IoLiTec \\
\hline Trihexyltetradecyl decanoate & {$\left[\mathrm{P}_{14,666}\right] \mathrm{Dec}$} & IoLiTec \\
\hline Choline dihydrogen citrate & [Choline]Cit & TCI \\
\hline Acetylcholine perchlorate & {$[$ Accholine $] \mathrm{ClO}_{4}$} & TCI \\
\hline 1-Hexyl-1,4-diaza[2,2,2]bicyclooctanium bis(trifluoromethylsulfonyl)imide & {$[\mathrm{HDABCO}] \mathrm{NTf}_{2}$} & IoLiTec \\
\hline
\end{tabular}

Manuf manufacturer, TCI Tokyo Kasei Kogyo 
with ethanol/benzene $(1 / 2, \mathrm{v} / \mathrm{v})$ for $24 \mathrm{~h}$ in a Soxhlet apparatus. The extractive-free wood flour was oven-dried at $105{ }^{\circ} \mathrm{C}$ for $24 \mathrm{~h}$ before use.

\section{Treatment with ionic liquids}

In a typical experiment, $3 \mathrm{~g}$ of ionic liquid was heated at $120{ }^{\circ} \mathrm{C}$. A $0.09 \mathrm{~g}$ portion of sample (wood flours, cellulose, cellobiose, and glucose) was then added to the ionic liquid, and the reaction media gently stirred. Zero hour of treatment was defined as the time the sample was added to the ionic liquid.

\section{Evaluation method}

The products from samples treated by ionic liquids were analyzed by high-performance liquid chromatography (HPLC). HPLC was carried out on a Shimadzu Prominence (Shimadzu, Kyoto, Japan) equipped with a pump (LC20AD), a column oven (CTO-20A), a refractive index detector (RID-10A), and an ultraviolet-visible detector (SPD-M20A). The samples for this analysis were prepared as follows: $40 \mu \mathrm{L}$ of the reaction medium was mixed with $360 \mu \mathrm{L}$ of distilled water and then filtered through a $0.45-\mu \mathrm{m}$ filter. The filtrates were analyzed under the following conditions: column, Shodex Sugar KS-801 (Showa Denko, Tokyo, Japan); flow rate, $1 \mathrm{~mL} / \mathrm{min}$; eluent, ultrapure water; column temperature, $80{ }^{\circ} \mathrm{C}$; and detector, refractive index detector and ultraviolet-visible detector set at $280 \mathrm{~nm}$.

The yield (wt $\%$ ) of products was calculated using the following equation:

Yield $(w t \%)=($ weight of product/weight of charged sample $)$

$$
\times 100 \text {. }
$$

The yield (mol\%) of product was calculated using the following equation:

$$
\begin{aligned}
& \text { Yield }(\mathrm{mol} \%) \\
& =(\text { moles of product } / \text { moles of hexose unit in charged material }) \\
& \quad \times 100 \text {. }
\end{aligned}
$$

The moles of hexose units in Japanese cedar were determined as follows. The Japanese cedar was added to distilled water, and sodium chlorite was added to give a final concentration of $0.09 \mathrm{M}$, along with a small quantity of acetic acid. The obtained reaction mixture was heated at $80{ }^{\circ} \mathrm{C}$, and further sodium chlorite and acetic acid were added to the reaction mixture every hour for $4 \mathrm{~h}$. The mixture was then filtered, to recover the holocellulose residue, which was then oven-dried at $105{ }^{\circ} \mathrm{C}$ for $24 \mathrm{~h}$ and weighed. The moles of hexose units were calculated on the basis of holocellulose recovered and the reported component ratio of hexose and pentose in Japanese cedar [24].
The monosaccharides in ionic liquid were analyzed by a Shimadzu GC-2014 gas chromatography (GC), with samples prepared as follows. The reaction medium $(20 \mu \mathrm{L})$ was homogeneously mixed with $200 \mu \mathrm{L}$ of acetonitrile and $20 \mu \mathrm{L}$ of pyridine. After drying with sodium sulfate, the obtained mixture was filtered using a $0.45-\mu \mathrm{m}$ filter. The filtrate $(150 \mu \mathrm{L})$ was silylated at room temperature by mixing with $100 \mu \mathrm{L}$ of BSTFA. The silylated sample was then analyzed by GC using an InertCap 17 capillary column (GL Sciences, Tokyo, Japan). The temperature program was $60{ }^{\circ} \mathrm{C} \quad(0 \rightarrow 1 \mathrm{~min}) ; \quad 60 \rightarrow 250{ }^{\circ} \mathrm{C}$ $(1 \rightarrow 10.5 \mathrm{~min})$; and $250{ }^{\circ} \mathrm{C}(10.5 \rightarrow 40 \mathrm{~min})$. Helium was used as the carrier gas at a flow rate of $1.0 \mathrm{~mL} / \mathrm{min}$. The temperatures of flame ionization detector and injector were 250 and $230{ }^{\circ} \mathrm{C}$, respectively.

Samples of Japanese cedar treated in ionic liquids were examined by light microscopy (BH-2, OLYMPUS, Tokyo, Japan) to investigate the reactivity of wood samples.

\section{Results and discussion}

Prior to studying the conversion of wood or cellulose into 5-HMF in various ionic liquids without a catalyst, we investigated the conversion of glucose, which is a constituent of cellulose. HPLC chromatograms of glucose treated in $\left[\mathrm{P}_{4442}\right] \mathrm{DEP}$ and [EMIM] $\mathrm{Cl}$ at $120{ }^{\circ} \mathrm{C}$ for $24 \mathrm{~h}$ are

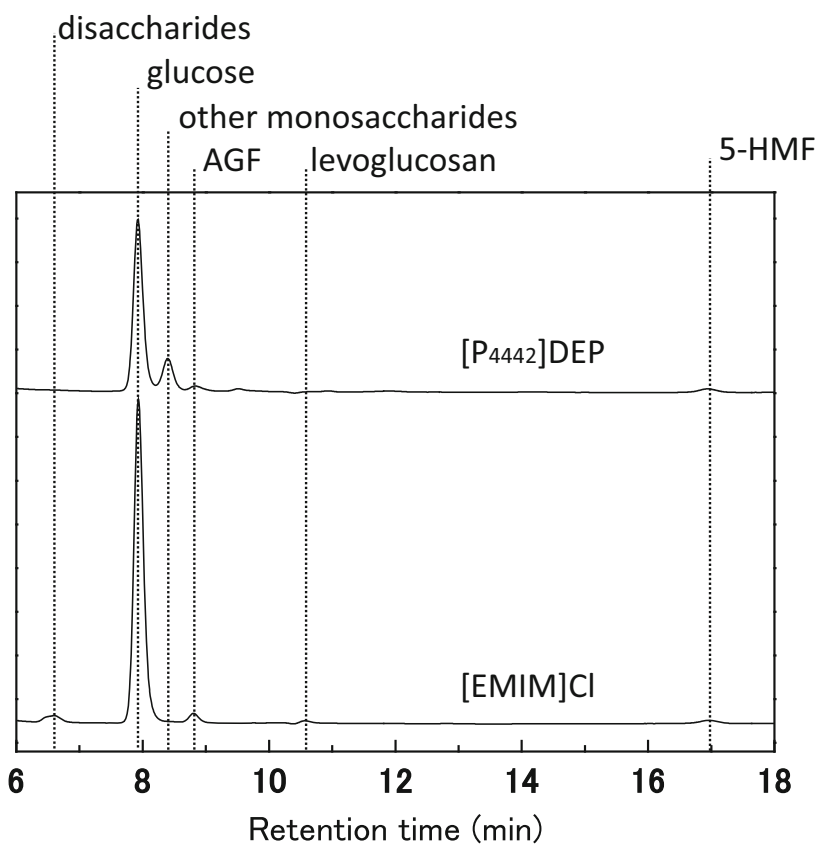

Fig. 1 HPLC chromatograms of glucose treated in $\left[\mathrm{P}_{4442}\right] \mathrm{DEP}$ (upper) and [EMIM]Cl (lower) for $24 \mathrm{~h}$ at $120^{\circ} \mathrm{C}$, detected by refractive index detector. Other mono saccharides mono saccharides other than glucose, $A G F$ 1,6-anhydro- $\beta$-D-glucofuranose, and 5-HMF 5-hydroxymethylfurfural 
shown in Fig. 1. Various compounds were detected, including 5-HMF, levoglucosan, and AGF as decomposition products. In addition, disaccharides were formed in [EMIM]Cl. In a previous study, Ohno and Miyafuji [25] showed that glucose is polymerized to disaccharides, such as maltose, nigerose, gentiobiose, and isomaltose in [EMIM]Cl. These disaccharides are thought to comprise the broad peak seen in the chromatogram in Fig. 1. On the other hand, monosaccharides other than glucose, which are referred to as "other monosaccharides" (OMS), were formed in $\left[\mathrm{P}_{4442}\right] \mathrm{DEP}$. GC analysis on OMS revealed the production of fructose. Therefore, it is possible that glucose was isomerized to fructose in ionic liquids.

Table 2 shows the yields of products from glucose after the treatments with ionic liquids at $120{ }^{\circ} \mathrm{C}$. [EMIM] $\mathrm{AlCl}_{4}$ and $\left[\mathrm{N}_{4444}\right] \mathrm{N}_{3}$ solidified and evaporated, respectively, during treatment, while [Choline]Cit becomes abnormally high in viscosity upon heating. Thus, data for these three ionic liquids could not be obtained. The results in Table 2 suggest that 5-HMF was formed from glucose without catalyst in [EMIM] $\mathrm{HSO}_{4}$, [EMIM]Tos, and [EMIM]Mes, which contain the sulfonyl group. Closer investigations
Table 2 Yield (wt\%) of products from glucose in various ionic liquids at $120{ }^{\circ} \mathrm{C}$

\begin{tabular}{|c|c|c|c|c|c|c|c|c|c|c|}
\hline \multirow[t]{2}{*}{ Ionic liquids } & \multicolumn{2}{|l|}{ OMS } & \multicolumn{2}{|l|}{ LG } & \multicolumn{2}{|l|}{ AGF } & \multicolumn{2}{|c|}{ 5-HMF } & \multicolumn{2}{|c|}{ Disaccharides } \\
\hline & $1 \mathrm{~h}$ & $24 \mathrm{~h}$ & $1 \mathrm{~h}$ & $24 \mathrm{~h}$ & $1 \mathrm{~h}$ & $24 \mathrm{~h}$ & $1 \mathrm{~h}$ & $24 \mathrm{~h}$ & $1 \mathrm{~h}$ & $24 \mathrm{~h}$ \\
\hline$[\mathrm{MIM}] \mathrm{NTf}_{2}$ & n.d. & n.d. & 15.0 & 12.0 & 2.2 & 1.5 & 0.0 & 0.0 & n.d. & n.d. \\
\hline$[\mathrm{EIM}] \mathrm{NO}_{3}$ & n.d. & 1.5 & 4.7 & 2.0 & 2.3 & 1.5 & 0.0 & 0.0 & 6.5 & n.d. \\
\hline [DMIM]DMP & 4.8 & 1.1 & 0.6 & 0.7 & n.d. & 0.6 & n.d. & n.d. & n.d. & n.d. \\
\hline [DMIM]BOB & n.d. & n.d. & n.d. & n.d. & n.d. & n.d. & n.d. & 0.0 & n.d. & n.d. \\
\hline [EMIM]Cl & n.d. & n.d. & n.d. & 0.6 & n.d. & 1.2 & 0.1 & 1.3 & 0.3 & 1.7 \\
\hline$\left[\mathrm{EMIM} \mathrm{HSO}_{4}\right.$ & n.d. & n.d. & n.d. & n.d. & n.d. & n.d. & 2.3 & 6.4 & n.d. & n.d. \\
\hline$[\mathrm{EMIM}] \mathrm{MPO}_{4}$ & n.d. & 5.8 & 1.9 & 2.7 & n.d. & n.d. & 0.0 & 0.0 & n.d. & n.d. \\
\hline [EMIM]Ac & 1.8 & n.d. & 0.1 & 0.4 & 0.4 & 0.5 & n.d. & n.d. & n.d. & n.d. \\
\hline$\left[\mathrm{EMIM} \mathrm{PF}_{6}\right.$ & n.d. & n.d. & n.d. & n.d. & n.d. & 11.8 & n.d. & n.d. & n.d. & n.d. \\
\hline$[\mathrm{EMIM}] \mathrm{AlCl}_{4}$ & $-^{\mathrm{a}}$ & $-^{\mathrm{a}}$ & ${ }^{\mathrm{a}}$ & $-^{\mathrm{a}}$ & $-^{\mathrm{a}}$ & $-^{\mathrm{a}}$ & $-{ }^{\mathrm{a}}$ & $-^{\mathrm{a}}$ & $-^{\mathrm{a}}$ & $-{ }^{\mathrm{a}}$ \\
\hline [EMIM]TCB & n.d. & n.d. & n.d. & 3.5 & n.d. & 0.3 & n.d. & n.d. & n.d. & 6.1 \\
\hline [EMIM]Tos & n.d. & n.d. & n.d. & n.d. & 22.2 & n.d. & 4.3 & 3.2 & 13.2 & n.d. \\
\hline [EMIM]Mes & 1.3 & n.d. & 18.7 & 1.4 & 8.8 & 0.9 & 1.2 & 2.6 & 10.1 & 0.7 \\
\hline [BMIM]SCN & n.d. & 3.1 & n.d. & n.d. & n.d. & n.d. & 0.0 & 0.0 & n.d. & n.d. \\
\hline$[\mathrm{BMIM}] \mathrm{BF}_{4}$ & 0.8 & 0.9 & 19.8 & 23.2 & n.d. & n.d. & 0.0 & 0.0 & n.d. & n.d. \\
\hline [BPr]FSI & n.d. & n.d. & n.d. & 0.3 & n.d. & 0.1 & n.d. & n.d. & 0.3 & 2.3 \\
\hline$[\mathrm{BPr}] \mathrm{PF}_{6}$ & n.d. & n.d. & n.d. & n.d. & 1.3 & 2.7 & 0.0 & 0.1 & n.d. & n.d. \\
\hline$[\mathrm{MPPyr}] \mathrm{PF}_{6}$ & n.d. & 0.9 & n.d. & n.d. & n.d. & n.d. & n.d. & n.d. & n.d. & 0.1 \\
\hline [MPPip]PF 6 & n.d. & n.d. & n.d. & n.d. & n.d. & n.d. & n.d. & n.d. & n.d. & 0.2 \\
\hline$\left[\mathrm{N}_{4444}\right] \mathrm{Cl}$ & n.d. & n.d. & n.d. & 0.8 & n.d. & 1.6 & n.d. & 0.0 & n.d. & 1.3 \\
\hline$\left[\mathrm{N}_{4444}\right] \mathrm{Br}$ & n.d. & n.d. & n.d. & n.d. & n.d. & 0.5 & n.d. & 0.3 & n.d. & 0.2 \\
\hline$\left[\mathrm{N}_{4444}\right] \mathrm{Cl}_{2} \mathrm{Br}$ & n.d. & n.d. & n.d. & n.d. & 0.3 & n.d. & n.d. & n.d. & n.d. & n.d. \\
\hline$\left[\mathrm{N}_{4444}\right] \mathrm{N}_{3}$ & $-^{\mathrm{b}}$ & $-^{\mathrm{b}}$ & $-{ }^{\mathrm{b}}$ & $-^{\mathrm{b}}$ & $-{ }^{\mathrm{b}}$ & $-^{\mathrm{b}}$ & $-{ }^{\mathrm{b}}$ & $-^{\mathrm{b}}$ & $-^{\mathrm{b}}$ & $-{ }^{\mathrm{b}}$ \\
\hline$\left[\mathrm{N}_{4444}\right] \mathrm{Sal}$ & 12.6 & 9.8 & n.d. & n.d. & n.d. & 0.9 & 0.0 & 0.1 & n.d. & n.d. \\
\hline$\left[\mathrm{P}_{4442}\right] \mathrm{DEP}$ & 1.1 & 7.0 & n.d. & 0.3 & 0.1 & 0.6 & 0.0 & 1.4 & n.d. & n.d. \\
\hline$\left[\mathrm{P}_{14,666}\right] \mathrm{PF}_{6}$ & n.d. & 0.8 & n.d. & n.d. & n.d. & 0.1 & n.d. & 0.1 & n.d. & n.d. \\
\hline$\left[\mathrm{P}_{14,666}\right] \mathrm{Dec}$ & 1.8 & n.d. & n.d. & n.d. & 0.1 & n.d. & n.d. & n.d. & n.d. & n.d. \\
\hline [Choline]Cit & $-^{\mathrm{c}}$ & $-^{\mathrm{c}}$ & $-^{\mathrm{c}}$ & $-^{\mathrm{c}}$ & $-^{\mathrm{c}}$ & $-^{\mathrm{c}}$ & $-^{\mathrm{c}}$ & $-^{\mathrm{c}}$ & $-^{c}$ & $-^{\mathrm{c}}$ \\
\hline$[$ Accholine $] \mathrm{ClO}_{4}$ & 1.3 & 2.1 & 0.4 & 0.5 & n.d. & n.d. & n.d. & 0.0 & n.d. & n.d. \\
\hline$\left[\mathrm{HDABCO} \mathrm{NTf}_{2}\right.$ & n.d. & n.d. & n.d. & n.d. & n.d. & n.d. & 0.0 & 0.0 & n.d. & n.d. \\
\hline
\end{tabular}

OMS monosaccharides except for glucose, $L G$ levoglucosan, $A G F$ 1,6-anhydro- $\beta$-D-glucofuranose, 5 - $H M F$ 5-hydroxymethylfurfural, $n . d$. not detected

${ }^{\text {a }}$ Solidified during treatment

${ }^{\mathrm{b}}$ Evaporated during treatment

c Viscosity becomes abnormally high upon heating 

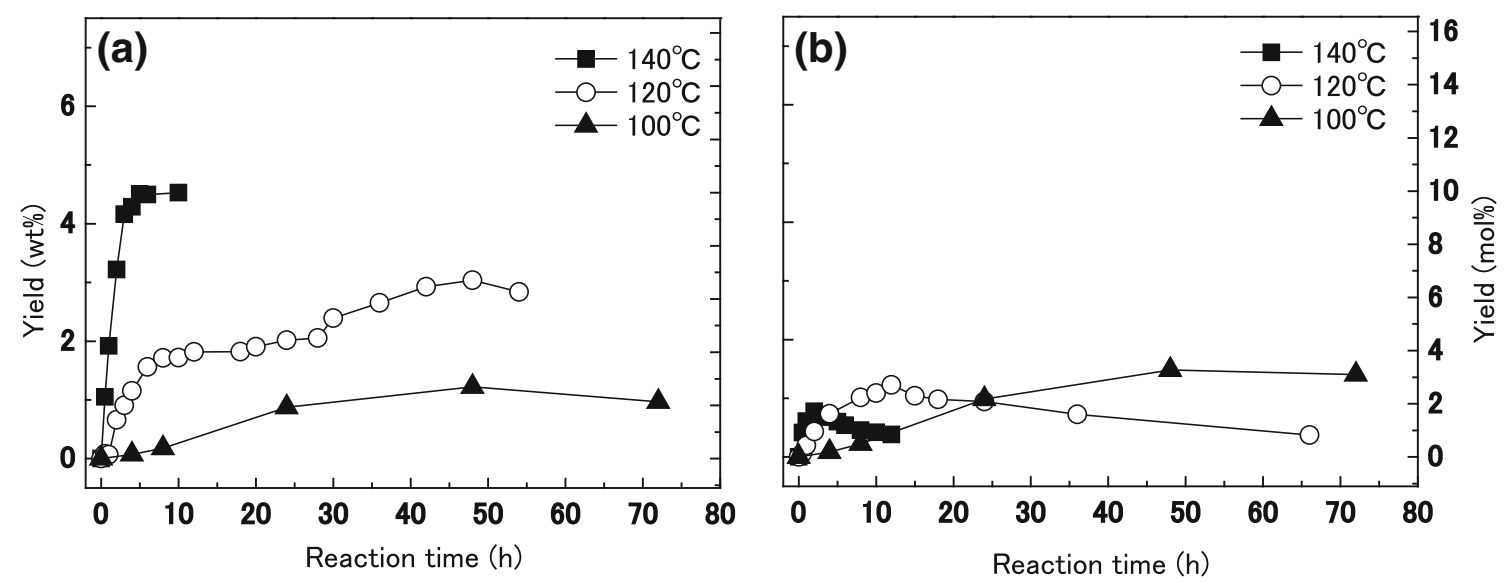

Fig. 2 Changes in 5-HMF yield from Japanese cedar treated in a [EMIM] $\mathrm{HSO}_{4}$ and $\mathbf{b}[\mathrm{EMIM}]$ Tos at various reaction temperatures
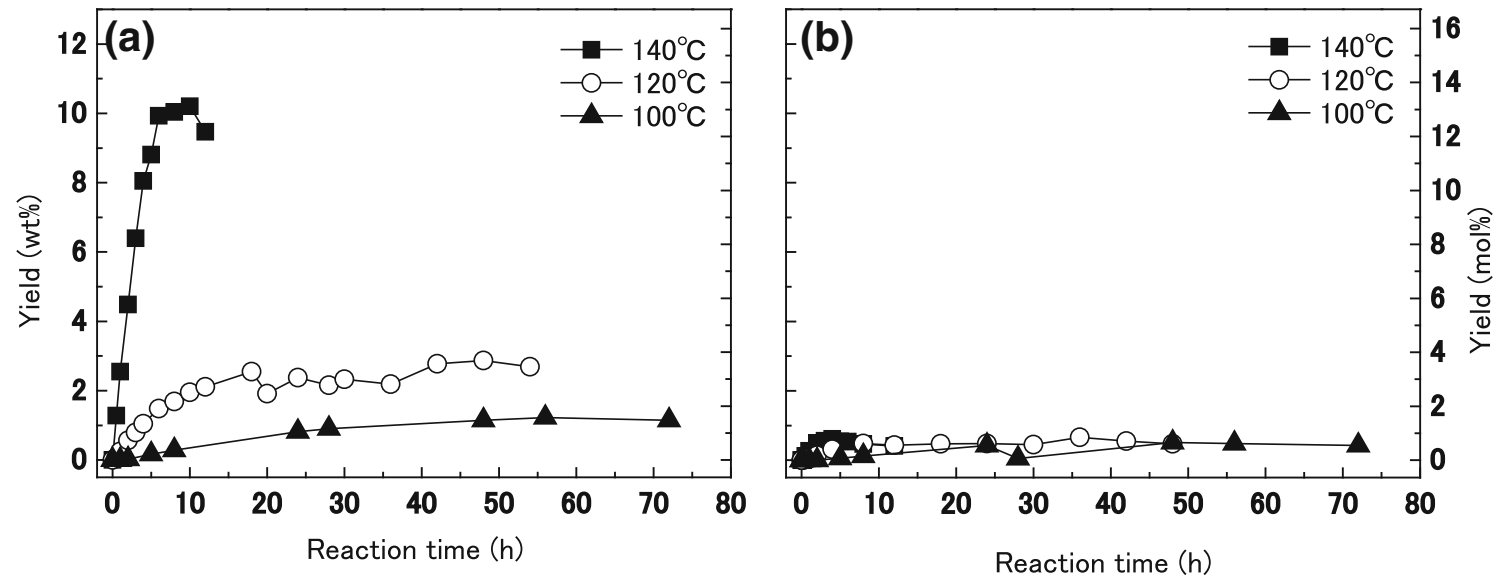

Fig. 3 Changes in 5-HMF yields from cellulose treated in a [EMIM] $\mathrm{HSO}_{4}$ and $\mathbf{b}$ [EMIM]Tos at various reaction temperatures
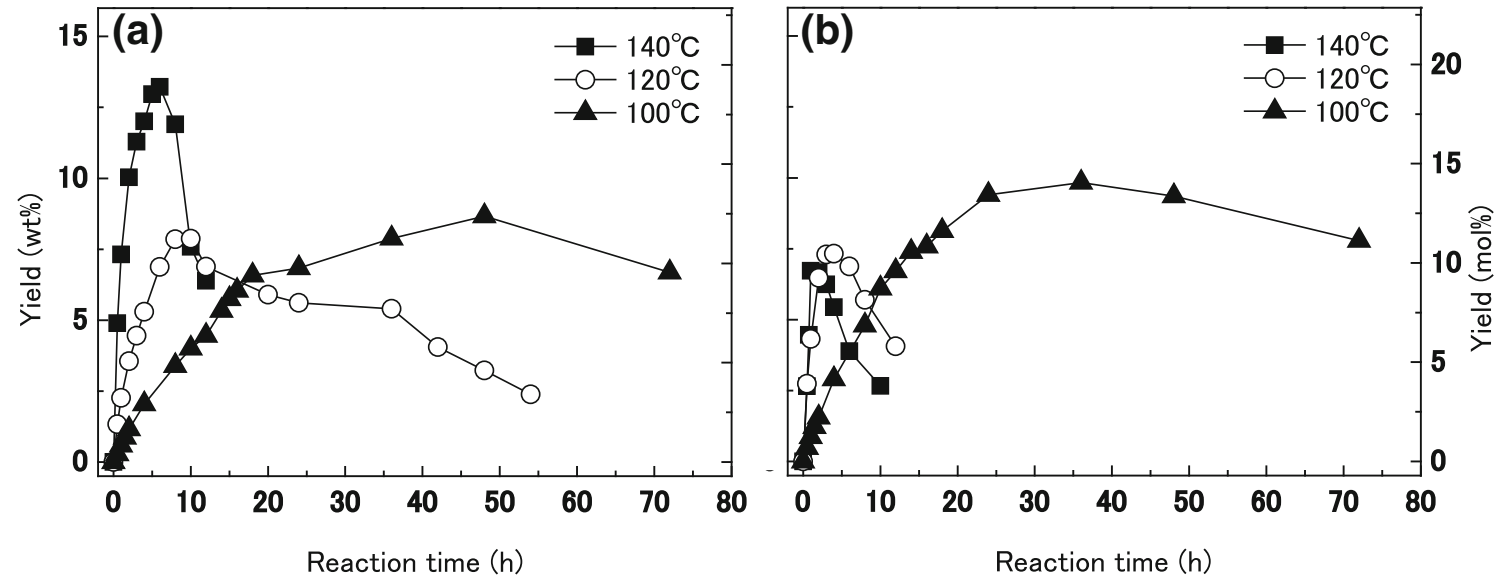

Fig. 4 Changes in 5-HMF yields from glucose treated in a $[\mathrm{EMIM}] \mathrm{HSO}_{4}$ and $\mathbf{b}[\mathrm{EMIM}] \mathrm{T}$ os at various reaction temperatures

show that glucose was sparingly converted into the various chemicals listed in Table 2 in hydrophobic ionic liquids, such as [BPr]FSI, $\left[\mathrm{P}_{14,666}\right]$ Dec, and [HDABCO $] \mathrm{NTf}_{2}$.
[DMIM]DMP and [ $\mathrm{N}_{4444}$ ]Sal effectively converted glucose into other monosaccharides, while glucose was polymerized to disaccharides in $[\mathrm{EMIM}] \mathrm{NO}_{3},[\mathrm{EMIM}] \mathrm{Tos}$, and 
[EMIM]Mes. [BMIM]BF 4 and [EMIM]Tos can convert glucose into levoglucosan and AGF with high yields, respectively. These reactions of glucose in various ionic liquids are interesting, and future research to optimize the production of these compounds is necessary.

Based on the results shown above, conversions of wood into 5-HMF in [EMIM] $\mathrm{HSO}_{4}$ and [EMIM]Tos were studied. Changes in 5-HMF yield from wood (Japanese cedar) in $[\mathrm{EMIM}] \mathrm{HSO}_{4}$ and $[\mathrm{EMIM}] \mathrm{Tos}$ at various reaction temperatures are shown in Fig. 2a, b, respectively. In the case of $[\mathrm{EMIM}] \mathrm{HSO}_{4}$, the yield of 5-HMF reached a maximum at $4.5 \mathrm{wt} \%$ with treatment for $10 \mathrm{~h}$ at $140{ }^{\circ} \mathrm{C}$. At $120{ }^{\circ} \mathrm{C}$, the yield gradually increased to $2.5 \mathrm{wt} \%$. However, 5-HMF was formed below a $1.0 \mathrm{wt} \%$ yield at $100{ }^{\circ} \mathrm{C}$. The 5-HMF yield thus increased with temperature for [EMIM] $\mathrm{HSO}_{4}$, but it was below $2 \mathrm{wt} \%$ in [EMIM]Tos at all reaction temperatures, as shown in Fig. 2b. It was found that wood was poorly converted into 5-HMF in [EMIM]Tos when compared with its conversion in [EMIM] $\mathrm{HSO}_{4}$.

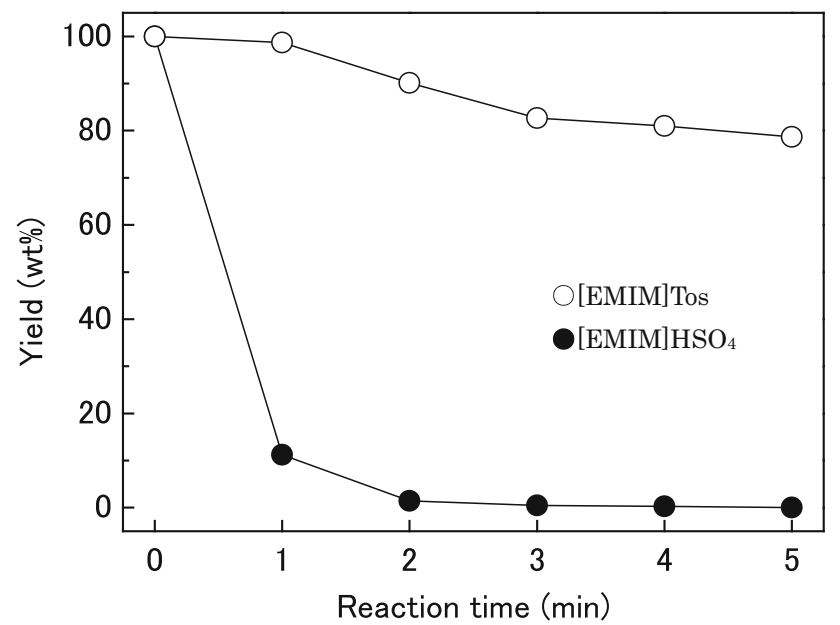

Fig. 5 Changes in cellobiose yields during the treatment with [EMIM]Tos and [EMIM] $\mathrm{HSO}_{4}$ at $120{ }^{\circ} \mathrm{C}$
Cellulose and glucose were treated in [EMIM] $\mathrm{HSO}_{4}$ and [EMIM]Tos to investigate the difference in their 5-HMF yields. Changes in 5-HMF yields for cellulose treated in $\left[\right.$ EMIM] $\mathrm{HSO}_{4}$ and [EMIM]Tos at various reaction temperatures are shown in Fig. 3. The yield of 5-HMF reached a maximum at $10.2 \mathrm{wt} \%$ with treatment in [EMIM] $\mathrm{HSO}_{4}$ for $10 \mathrm{~h}$ at $140{ }^{\circ} \mathrm{C}$, as shown in Fig. 3a. At 100 and $120{ }^{\circ} \mathrm{C}$, the yields increased slightly from 1.2 to $2.5 \mathrm{wt} \%$, respectively, with prolonged reaction time. 5-HMF was also found to be effectively produced from cellulose in [EMIM] $\mathrm{HSO}_{4}$ at $140{ }^{\circ} \mathrm{C}$ but was not produced in significant quantities in [EMIM]Tos at any reaction temperature, as shown in Fig. 3b. Figure 4 shows the changes in 5-HMF yield from glucose treated in [EMIM] $\mathrm{HSO}_{4}$ and [EMIM]Tos at various reaction temperatures. The yield reached a maximum of $13.2 \mathrm{wt} \%$ with treatment in [EMIM] $\mathrm{HSO}_{4}$ for $6 \mathrm{~h}$ at $140{ }^{\circ} \mathrm{C}$, as shown in Fig. 4a. However, the yields were $8.6 \mathrm{wt} \%$ after $48 \mathrm{~h}$ at $100{ }^{\circ} \mathrm{C}$ and $7.8 \mathrm{wt} \%$ after $10 \mathrm{~h}$ at $120^{\circ} \mathrm{C}$, respectively. Thus, although glucose can be converted into 5-HMF in [EMIM] $\mathrm{HSO}_{4}$ at all reaction temperatures, yields can be increased with higher reaction temperatures and shorter reaction times. It was also found that the yield decreased more quickly at higher reaction temperature, because 5-HMF in [EMIM] $\mathrm{HSO}_{4}$ is thought to be unstable and decomposes easily as the reaction temperature increases. Meanwhile, the yield of 5-HMF from glucose in [EMIM]Tos reached a maximum of 9.8 wt $\%$ through treatment for $36 \mathrm{~h}$ at $100{ }^{\circ} \mathrm{C}$, as shown in Fig. 4b. At 120 and $140{ }^{\circ} \mathrm{C}$, the maximum yields were 7.3 and $6.7 \mathrm{wt} \%$, respectively. 5-HMF was formed at all reaction temperatures when glucose was treated in [EMIM]Tos, but it readily decomposes as the reaction temperature increases.

These results show that wood and cellulose are only slightly converted into 5-HMF in [EMIM]Tos, although glucose can be converted. Previous studies reported that wood is converted into 5-HMF through hexoses, such as (a)

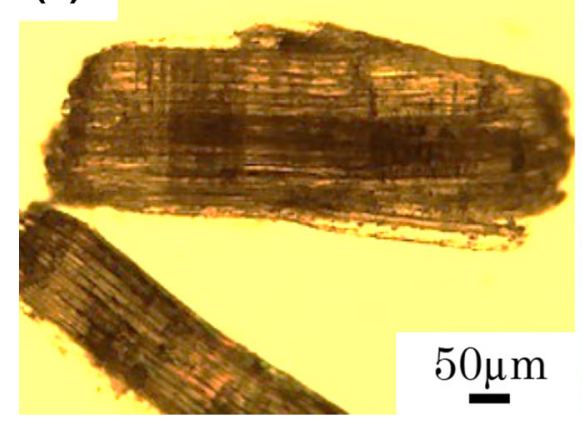

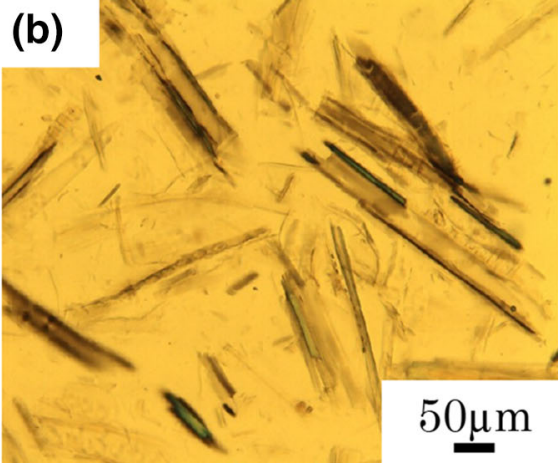

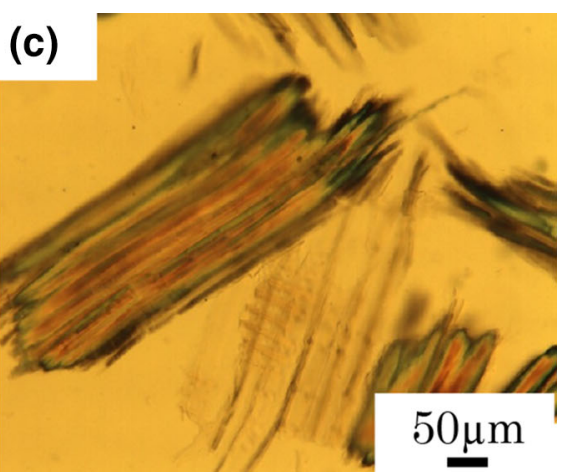

Fig. 6 Light microscope images of wood treated with ionic liquid for $4 \mathrm{~h}$ at $120^{\circ} \mathrm{C}$, a untreated, b [EMIM]HSO 4 , and $\mathbf{c}[\mathrm{EMIM}] \mathrm{Tos}$ 
glucose [26-28]. Thus, it is possible that [EMIM]Tos can only partially decompose polysaccharides. To investigate the ability of [EMIM]Tos and [EMIM] $\mathrm{HSO}_{4}$ for decomposition, cellobiose was treated in [EMIM]Tos and [EMIM] $\mathrm{HSO}_{4}$ at $120{ }^{\circ} \mathrm{C}$. Changes in cellobiose yields are shown in Fig. 5. It is found that cellobiose is much stable in [EMIM]Tos, although it disappears quickly in [EMIM] $\mathrm{HSO}_{4}$. These results suggest that 5 -HMF is difficult to produce from wood using [EMIM]Tos, because it has a low ability for decomposing cellulose.

To investigate the reaction of wood in [EMIM] $\mathrm{HSO}_{4}$ and [EMIM]Tos, wood particles samples were treated in these ionic liquids for $4 \mathrm{~h}$ at $120{ }^{\circ} \mathrm{C}$ and examined by light microscopy, as shown in Fig. 6. Wood particles treated with [EMIM] $\mathrm{HSO}_{4}$ decreased in size, as shown in Fig. 6b, but those treated with [EMIM]Tos maintained their original sizes, as shown in Fig. 6c. These results suggest that solubility and reactivity of wood in [EMIM] $\mathrm{HSO}_{4}$ is higher than in [EMIM]Tos. Thus, we believe that the yield of 5 -HMF from wood in [EMIM] $\mathrm{HSO}_{4}$ will be higher than that in [EMIM]Tos.

\section{Conclusion}

Glucose can be converted into 5-HMF without a catalyst in ionic liquids that contain sulfonyl groups, such as $\left[\right.$ EMIM] $\mathrm{HSO}_{4}$ and [EMIM]Tos. However, wood and cellulose were poorly converted into 5-HMF in [EMIM]Tos, because it has a low ability to decompose wood and cellulose. Among various ionic liquids tested, [EMIM] $\mathrm{HSO}_{4}$ was notable for its ability to convert wood and cellulose into 5 - $\mathrm{HMF}$ at $140{ }^{\circ} \mathrm{C}$ without a catalyst, probably because it has a superior ability to solubilize wood.

\section{References}

1. Ragauskas AJ, Williams CK, Davison BH, Britovsek G, Cairney J, Eckert CA, Frederick WJ, Hallett JP, Leak DJ, Liotta CL, Mielenz JR, Murphy R, Templer R, Tschaplinski T (2006) The path forward for biofuels and biomaterials. Science 311:484-489

2. Rajagopal D, Sexton SE, Roland-Holst D, Zilberman D (2007) Challenge of biofuel: filling the tank without emptying the stomach? Environ Res Lett 2:1-9

3. Amidon TE (2006) The biorefinery in New York: woody biomass into commercial ethanol. Pulp Pap Can 107:47-50

4. Gellerstedt G, Sjöholm E, Brodin I (2010) The wood-based biorefinery: a source of carbon fiber? Open Agric J 3:119-124

5. Zhu JY, Pan X, Zalesny RS (2010) Pretreatment of woody biomass for biofuel production:energy efficiency, technologies, and recalcitrance. Appl Microbiol Biotechnol 87:847-857

6. Werpy T, Petersen G (2004) Top value added chemicals from biomass. US Department of Energy (DOE), Golden, pp 6-12
7. Dutta S, De S, Saha B (2013) Advances in biomass transformation to 5-hydroxymethylfurfural and mechanistic aspects. Biomass Bioenergy 55:355-369

8. Kuster FMB (1990) 5-Hydroxymethylfurfural (HMF), a review focussing on its manufacture. Starch 42:314-321

9. Lewkowski J (2001) Synthesis, chemistry and applications of 5-hydroxymethyl-furfural and its derivatives. Arkivoc 2001:17-54

10. Stark A (2011) Ionic liquids in the biorefinery: a critical assessment of their potential. Energy Environ Sci 4:24-27

11. Olivier-Bourbigou H, Magna L, Morvan D (2010) Ionic liquids and catalysis: recent progress from knowledge to applications. Appl Catal A 373:1-12

12. Ohno H, Fukaya Y (2009) Task specific ionic liquids for cellulose technology. Chem Lett 38:1-4

13. Earle MJ, Seddon KR (2000) Ionic liquids. Green solvents for the future. Pure Appl Chem 72:1391-1398

14. Greaves TL, Drummond CJ (2008) Protic ionic liquids: properties and applications. Chem Rev 108:206-237

15. Xing LJ, Hui LX, Fu WL, Ning Z (2012) Ionic liquids: efficient solvent and medium for the transformation of renewable lignocelluloses. Sci China Chem 55:1500-1508

16. Zhao H, Holladay JE, Brown H, Zhang ZC (2007) Metal chlorides in ionic liquid solvents convert sugars to 5-hydroxymethylfurfural. Science 316:1597-1600

17. Takagaki A, Nishimura S, Ebitani K (2012) Catalytic transformations of biomass-derived materials into value-added chemicals. Catal Surv Asia 16:164-182

18. Eminov S, Wilton-Ely JDET, Hallett JP (2014) Highly selective and near-quantitative conversion of fructose to 5-hydroxymethylfurfural using mildly acidic ionic liquids. ACS Sustain Chem Eng 2:978-981

19. Zhao H, Brown HM, Holladay JE, Zhang ZC (2012) Prominent roles of impurities in ionic liquid for catalytic conversion of carbohydrates. Top Catal 55:33-37

20. Su Y, Brown HM, Huang X, Zhou X, Amonette JE, Zhang ZC (2009) Single-step conversion of cellulose to 5-hydroxymethylfurfural (HMF), a versatile platform chemical. Appl Catal A 361:117-122

21. Hu L, Zhao G, Hao W, Tang X, Sun Y, Lin L, Liu S (2012) Catalytic conversion of biomass-derived carbohydrates into fuels and chemicals via furanic aldehydes. RSC Adv 2:11184-11206

22. Lima S, Neves P, Antunes MM, Pillinger M, Ignatyev N, Valente AA (2009) Conversion of mono/di/polysaccharides into furan compounds using 1-alkyl-3-methylimidazolium ionic liquids. Appl Catal A 363:93-99

23. Zakrzewska ME, Bogel-Łukasik E, Bogel-Łukasik R (2011) Ionic liquid-mediated formation of 5-hydroxymethylfurfurals-a promising biomass-derived building block. Chem Rev 111:397-417

24. Yamasaki T, Enomoto A, Kato A, Ishii T, Shimizu K (2011) Structural unit of xylans from sugi (Cryptomeria japonica) and hinoki (Chamaecyparis obtusa). J Wood Sci 57:76-84

25. Ohno E, Miyafuji H (2014) Production of disaccharides from glucose by treatment with an ionic liquid, 1-ethyl-3-methylimidozolium chloride. J Wood Sci 61:165-170

26. Binder JB, Raines RT (2009) Simple chemical transformation of lignocellulosic biomass into furans for fuels and chemicals. J Am Chem Soc 131:1979-1985

27. Tuteja J, Nishimura S, Ebitani K (2012) One-pot synthesis of furans from various saccharides using a combination of solid acid and base catalysts. Bull Chem Soc Jap 85:275-281

28. Qi X, Watanabe M, Aida TM, Smith RL Jr (2011) Catalytic conversion of cellulose into 5-hydroxymethylfurfural in high yields via a two-step process. Cellulose 18:1327-1333 